\title{
Vegetarian Diet Ameliorates Symptoms of Atopic Dermatitis through Reduction of the Number of Peripheral Eosinophils and of PGE2 Synthesis by Monocytes
}

\author{
Toshio Tanaka ${ }^{1)}$, Katsuyasu Kouda ${ }^{2)}$, Mayumi Kotani ${ }^{3)}$, Akira Takeuchi $^{3)}$, Toshio Tabei ${ }^{3)}$, \\ Yukimitsu Masamoto ${ }^{4)}$, Harunobu Nakamura ${ }^{2)}$, Masahiro Takigawa ${ }^{5)}$, \\ Masaki Suemura $^{1)}$, Hiroichi Takeuchi ${ }^{2)}$ and Mitsuo Kouda ${ }^{6)}$ \\ 1) Department III of Internal Medicine, Osaka University Medical School \\ 2) Department of Public Health, Hamamatsu University School of Medicine \\ 3) Research and Development Center, Sunstar Inc. \\ 4) Osaka Seikei Women's College \\ 5) Department of Dermatology, Hamamatsu University School of Medicine \\ 6) Kouda Clinics
}

\begin{abstract}
Many patients with atopic dermatitis are dissatisfied with conventional treatments based on topical steroids and have experienced some traditional remedies and alternative therapies. However, most of such therapies have not been evaluated scientifically and clinically by specialists. This study was designed to assess whether a certain vegetarian diet might be effective for atopic dermatitis and if so, to identify the mechanisms of this remedy through analyses of immunological parameters. An open-trial study was carried out in twenty patients with atopic dermatitis. An improvement of dermatitis was evaluated by SCORAD index and serological and immunological parameters were monitored. After a twomonth treatment, the severity of dermatitis was strikingly inhibited, as assessed by SCORAD index and serological parameters including LDH5 activity and a number of peripheral eosinophils. A sharp reduction in eosinophils and neutrophils was observed prior to improvement in the skin inflammation. In addition, PGE2 production by peripheral blood mononuclear cells was reduced by this treatment. In contrast, serum IgE levels did not change during the same period. Although this study is an open-trial one, it suggests that this treatment may be useful for the treatment of adult patients with severe atopic dermatitis. J Physiol Anthropol 20 (6): 353-361, 2001 http:// www.jstage.jst.go.jp/en/
\end{abstract}

Keywords: atopic dermatitis, vegetarian diet, eosinophil, PGE2

\section{Introduction}

Atopic dermatitis (AD) is a common disease and has recently been on the increase, especially in industrialized countries (Kay et al., 1994; Rudikoff, 1988; Williams, 1998). Recent basic immunological analyses of the pathogenesis of this disease have revealed that excess of differentiated Th2 cells might play major roles on the development of dermatitis and IgE synthesis (Cooper, 1994; Hamid et al., 1994; Grewe et al., 1998). In addition, barrier functions in atopic skins have been shown to be suppressed, regardless of immunological abnormality (Imokawa et al., 1991; Bos et al., 1994). The primary cause or causes, however, still remain to be determined. For the diagnosis and management of the disease, Hanifin and Rajka first proposed diagnostic criteria (Hanifin et al., 1980) and later other organizations including the Japanese Society of Dermatology established similar criteria or guidelines for AD (Przybilla et al., 1994; McHenry et al., 1995; Leung et al., 1997; Yamamoto, 1999).

Although it has been established that topical steroid therapy is crucial for this disease (Leung, 1997; GrahamBrown, 1997), many patients are still dissatisfied with its effectiveness and are worried about chronic use of this drug. Thus, especially in Japan, many patients have turned to traditional, alternative therapies (Endou, 1996). These regimens include ointments, bathing, various kinds of drinks, phototherapy, massages, acupuncture, botanical medicine and diets. It has been 
reported that 60 to $70 \%$ of adult patients with severe $\mathrm{AD}$ have experienced such alternatives. However, the effectiveness, adverse effects and the mechanisms of most of such alternative therapies have not been evaluated by dermatology or allergy specialists. In order to evaluate these "complementary and alternative" medicines, the center of Complementary and Alternative Medicine has recently been established at the National Institutes of Health in the USA (Eskinazi et al., 1998). If an alternative therapy is determined to be appropriate, it will be accepted clinically and scientifically by the organization. This study evaluates one particular alternative therapy based on Nishi's approach to health (Nishi, 1977). This therapy mainly consists of a lowenergy and vegetarian diet (Kouda, 1995). Previously we reported that a low-energy diet reduced inflammatory symptoms of patients with $\mathrm{AD}$ (Kouda et al., 2000). The aim of the present study was to identify the immunological mechanisms of the treatment for $\mathrm{AD}$.

\section{Methods}

\section{Patients}

Twenty patients ( 6 males and 14 females) aged 15 to 36 years (average: 25 years) with AD varying in severity from mild to serious were enrolled in the study. Five patients had a history of asthma and one patient suffered from concurrent asthma but the symptoms of this patient were mild and intermittent so that inhalation of steroids was not required. There were 10 patients who had suffered or were suffering from rhinitis. A family history of allergic diseases was reported in $65 \%$ of the patients. The mean age of onset of $\mathrm{AD}$ was 20 years (range: 0-29). All patients met Hanifin and Rajka's criteria for AD (Hanifin et al., 1980), and all patients except one had stopped taking all topical and/or systemic steroids and antihistamines at least 2 months before hospitalization. One male patient was diagnosed with suppurative lymphadenitis immediately before hospitalization and continued with antibiotic (minocycline hydrochloride) and antihistamine (a-chlorpheniramine maleate) therapy. This patient also received ranitidine hydrochloride.

\section{Informed consent}

Patients who were interested in entering this study received a full explanation of the purposes, treatment and requirements of the study one-month before hospitalization. Written informed consent was obtained from all patients and eligibility was confirmed by doctors of internal medicine and dermatology.

\section{Contents of therapy}

All patients were given identical meals. The diet consisted of a glass of fresh vegetable juice (corresponding to $250 \mathrm{~g}$ of fresh vegetables including
Spinach, Komatsuna, Cabbage, Pak-Choi, and Garland Chrysanthemum) at breakfast, brown rice porridge (corresponding to $80 \mathrm{~g}$ of brown rice) sprinkled with $5 \mathrm{~g}$ of kelp powder, tofu (wet weight approximately $200 \mathrm{~g}$ ) and $10 \mathrm{~g}$ of sesame paste for lunch and again for dinner. A daily requirement of $2.5 \mathrm{~g}$ of non-refined salt was added to the diet. The energy intake $(1,085 \mathrm{kcal})$ was $55 \%$ of recommended dietary allowance; protein was $75 \%$, calcium 180\%, iron 130\%, vitamin A 150\%, vitamin C $250 \%$, and vitamin E $110 \%$ of daily allowance. Instead of water, patients were given persimmon leaf tea (1-2 l/ day). This treatment was administered for two months in a private hospital.

\section{Clinical evaluation}

Recording and assessment of dermatological symptoms: Dermatological symptoms were assessed weekly by two doctors according to SCORAD method (European Task Force on Atopic Dermatitis, 1993). One week prior to study entry and weekly thereafter, the patients graded itching and sleep disturbance by completing a self-assessment questionnaire.

Blood tests: Blood samples for hematology were collected at the time of hospitalization ( 0 week), one month later (4th week), at discharge from the clinic (8th week) and at follow-up (2 month after discharge). LDH-5 was monitored in each serum sample. Whole blood analysis included hemoglobin, red blood cells, hematocrit, white blood cells and differential white blood cell count.

Analysis of immune index: The serum level of IgE and the synthesis of IL- 4 and IFN- $\gamma$ by peripheral blood mononuclear cells were measured at weeks 0 and 8 and at the time of follow-up ( 2 months after discharge). For IL-4 and IFN- $\gamma$ synthesis tests, mononuclear cells were diluted to $2 \times 10^{6}$ cells $/ \mathrm{ml}$ and stimulated by concanavalin-A (10 $\mu \mathrm{g} / \mathrm{ml}$ ) for 2 days. The concentrations of IL- 4 and IFN- $\gamma$ in the culture medium were then determined with the CLB Compact Interleukin 4 ELISA Kit (Central Laboratory of the Netherlands Red Cross Blood Transfusion Service, Amsterdam, The Netherlands) and the Endogen Human ELISA IFN- $\gamma$ (Endogen Inc., Cambridge, MA). IgE was measured by means of the sandwich ELISA method with two different anti-human IgE monoclonal antibodies (690 and 8-73) (Katada et al., 1996). The sensitivity of this test was more than $0.2 \mathrm{pg} / \mathrm{ml}$ for IL-4, 9-10 pg/ml for IFN$\gamma$ and $50 \mathrm{pg} / \mathrm{ml}$ for IgE. The PGE2 concentration in the culture medium without any stimulation was also measured by ELISA (Assay Designs Inc.,).

\section{Statistical analyses}

Paired t-test was used for determining significant differences in values between groups. Coefficients of correlation were calculated by Spearman's correlation analysis. 
Clinical and immunological evaluations of patients 2 months after the discharge

Since clinical and immunological examinations could be administered to only 17 out of 20 patients, the data showing comparison with those obtained at admission are thus limited to 17 subjects.

\section{Results}

Background of the patients participating in the study According to the RAST test, 17 of the patients showed sensitization to inhaled allergens such as house dust and tick antigen or food allergens such as soybean protein and egg white. The remaining three patients did not register positive RAST scores for these allergens. The serum IgE levels ranged from $26 \mathrm{IU} / \mathrm{ml}$ to $26,415 \mathrm{IU} / \mathrm{ml}$ (mean value $7,997 \mathrm{IU} / \mathrm{ml}$ ). Thirteen patients had serum IgE levels of more than $2,000 \mathrm{IU} / \mathrm{ml}$. On the basis of the demographic data and the IgE data, the profile of the patients included in this study was considered to be typical of adult patients with AD. As shown in Fig. 1, the mean SCORAD index at hospitalization was 49.9 and showed a positive and significant correlation with IgE serum level, number of peripheral eosinophils and LDH5 activity.
Amelioration of skin inflammation was accompanied by a reduction in LDH5 and number of peripheral eosinophils

As shown in Fig. 2, the SCORAD index showing the severity of all skin symptoms combined decreased significantly (mean scores: 49.9 at baseline and 27.4 at discharge) in the course of hospitalization. This index consists of both subjective symptoms and objective evaluation of skin inflammation, and both scores showed a gradual decrease. In addition, serological parameters including LDH5 activity and number of eosinophils decreased significantly during hospitalization as shown in Fig. 2. Eosinophils decreased from a mean of 423 cells/ $\mu \mathrm{l}$ at the time of hospitalization to 213 cells/ $\mu$ lat 8 weeks. LDH5 activity was $46 \mathrm{IU} / \mathrm{ml}$ at week 0 and decreased to 36 $\mathrm{IU} / \mathrm{ml}$ at 8 weeks.

\section{Eosinophils decreased prior to clinical improvement}

In order to clarify the mechanisms through which skin inflammation was suppressed, the number of eosinophils, which are inflammatory cells playing a major role in the development of dermatitis and skin irritability (Liferman et al., 1985; Kapp, 1993; Liferman et al., 1994), was counted every two weeks during the therapy. The
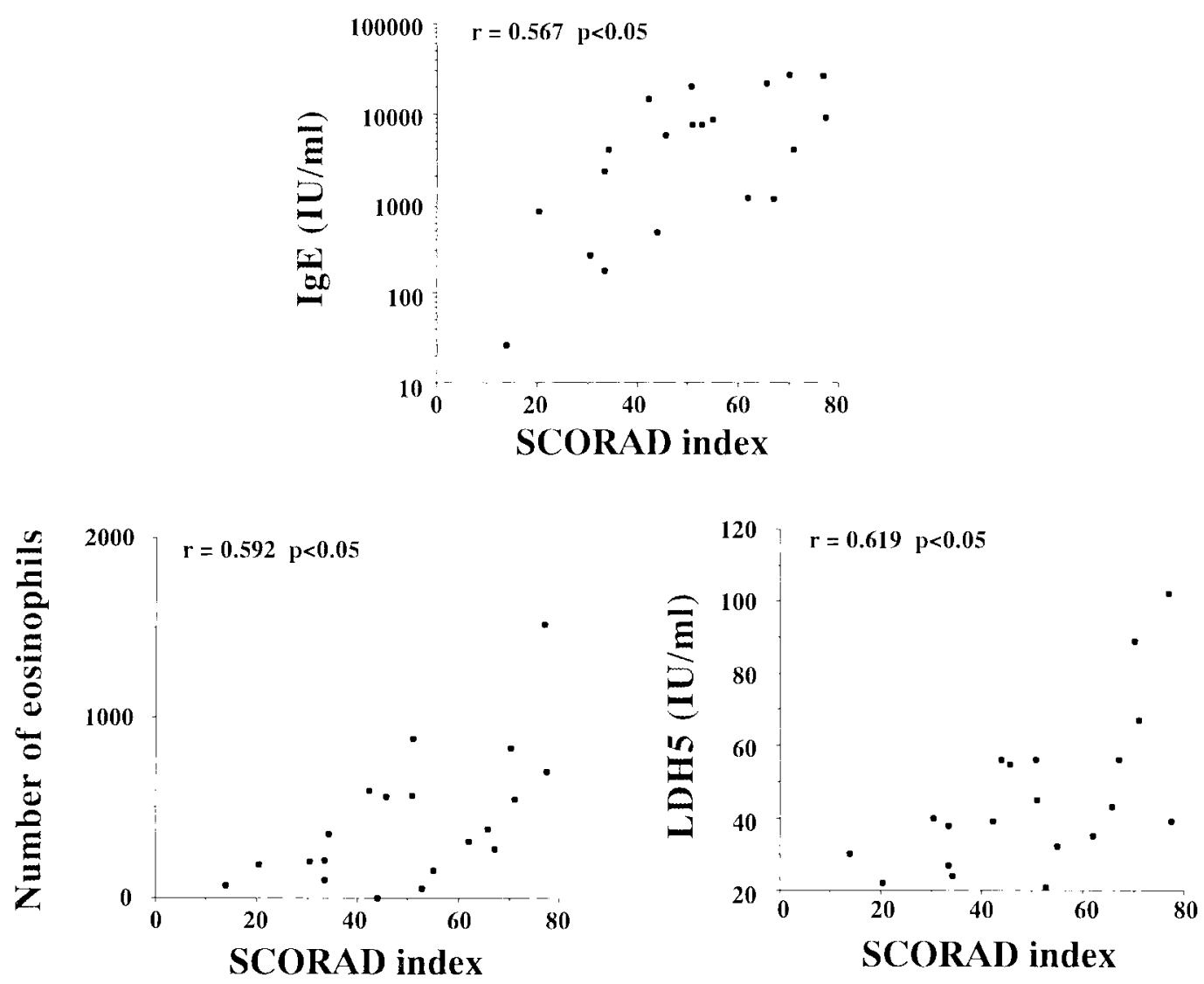

Fig. 1 Profile of atopic dermatitis patients enrolled in the study. The SCORAD index shows a positive correlation with serum IgE level, number of peripheral eosinophils and LDH5. 


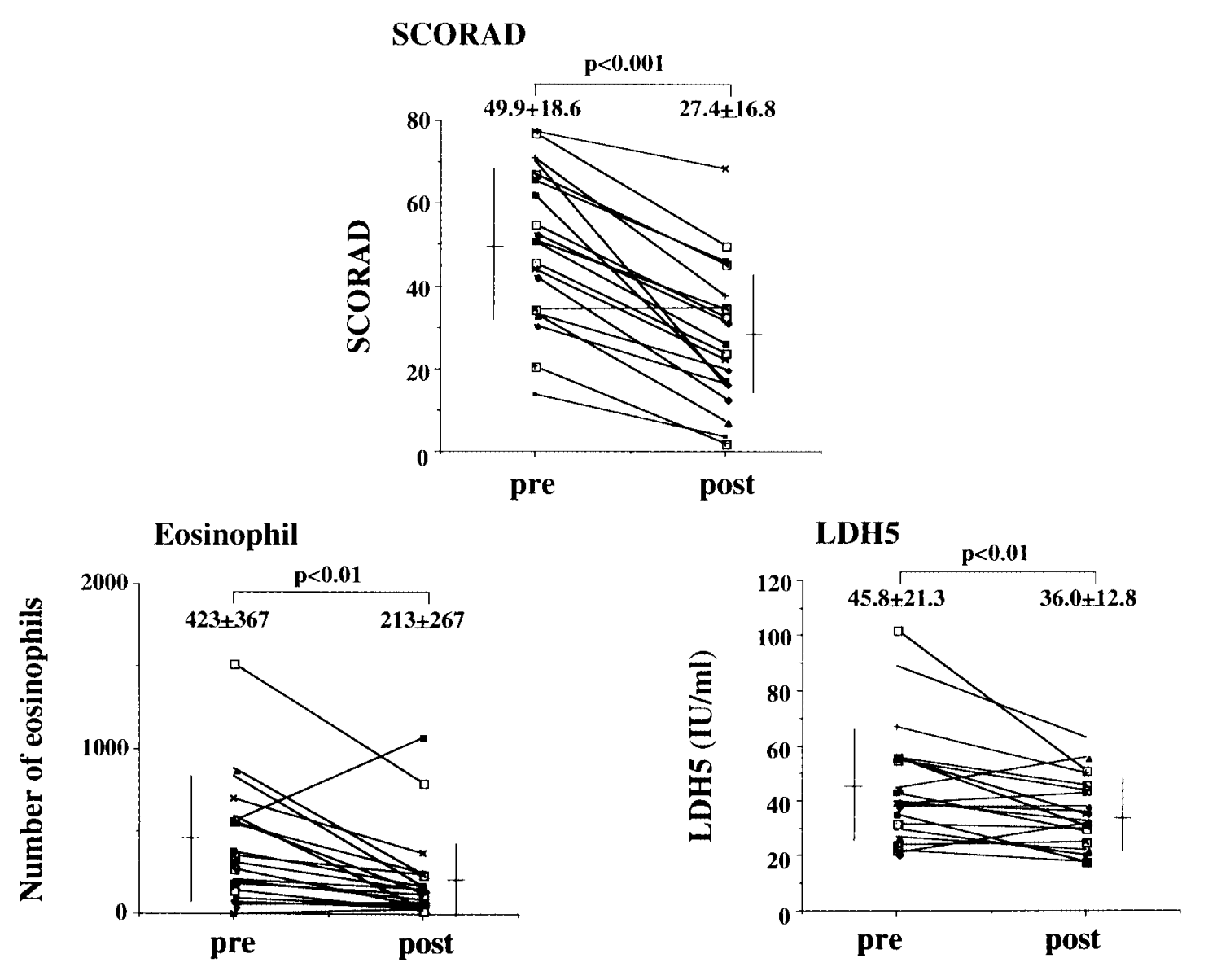

Fig. 2 The treatment for 2 months reduced SCORAD index, number of peripheral eosinophils and LDH5 activity. SCORAD index, number of eosinophils and LDH5 activity was measured before and after the treatment. All values changed significantly.

SCORAD index decreased at 2 weeks after hospitalization and then continued to decline slowly up to 8 weeks as shown in Fig. 3. In contrast, the number of eosinophils in the peripheral blood sharply dropped 2 weeks after the therapy. It reached its lowest level at 2 weeks and stayed there from then on.

Serum IgE was not significantly reduced during the hospitalization

It has been generally accepted that in $\mathrm{AD}$ IgE is greatly elevated and is associated with the development of dermatitis (Leung, 1993). Moreover, Th2 cells have been shown to play major roles in IgE elevation, allergic inflammation and skin hyper-sensitivity. Our study therefore examined changes in serum IgE and the capacity of T cells to produce IL- $4 / \mathrm{IFN}-\gamma$. Fig. 4 shows that the serum level of IgE showed positive correlation with the ratio of IL-4/IFN- $\gamma$ synthesis by Con-A-stimulated peripheral blood mononuclear cells. Although the SCORAD index improved, the serum level of IgE did not decrease significantly (Fig. 5). In addition, the allergen specific IgE titer (RAST score), which includes HD or food allergens, was not suppressed (data not shown). Surprisingly, the ratio of IL- $4 /$ IFN- $\gamma$ synthesis was somewhat raised as a result of this therapy, indicating that changes in the profiles of $\mathrm{T}$ cells (Th1 vs Th2 cells) may not be responsible for the clinical improvement.

Peripheral NK activity and number of neutrophils decreased during hospitalization

Fig. 6 demonstrates that peripheral NK activity decreased during the period. The number of neutrophils in the peripheral blood also decreased. It should be pointed out that this change in the number of neutrophils paralleled that of eosinophils, but that the actual number, except in one patient, was over $1,000 / \mu \mathrm{l}$.

\section{Spontaneous synthesis of PGE2 was inhibited}

Finally, PGE2 synthesis by peripheral blood mononuclear cells was studied, since it has been shown that over-synthesis of PGE2 by monocytes is found in patients with $\mathrm{AD}$ and that this molecule possibly 


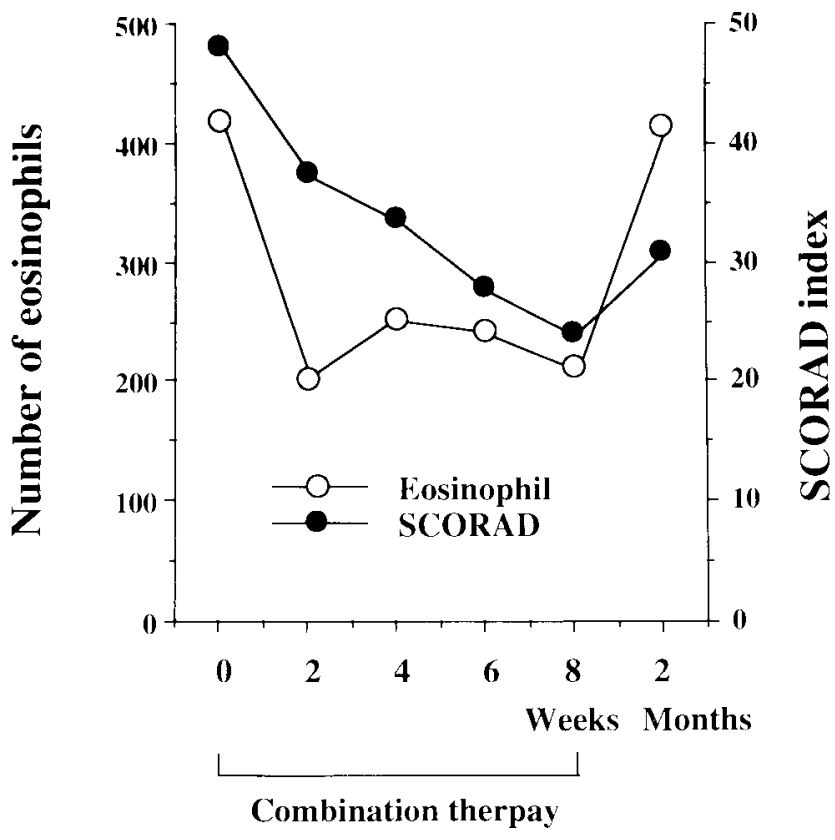

Fig. 3 The number of peripheral blood eosinophils was sharply decreased prior to change in the SCORAD index. SCORAD index and number of peripheral eosinophils (cells/ $\mu$ l) were measured every two weeks during the treatment.

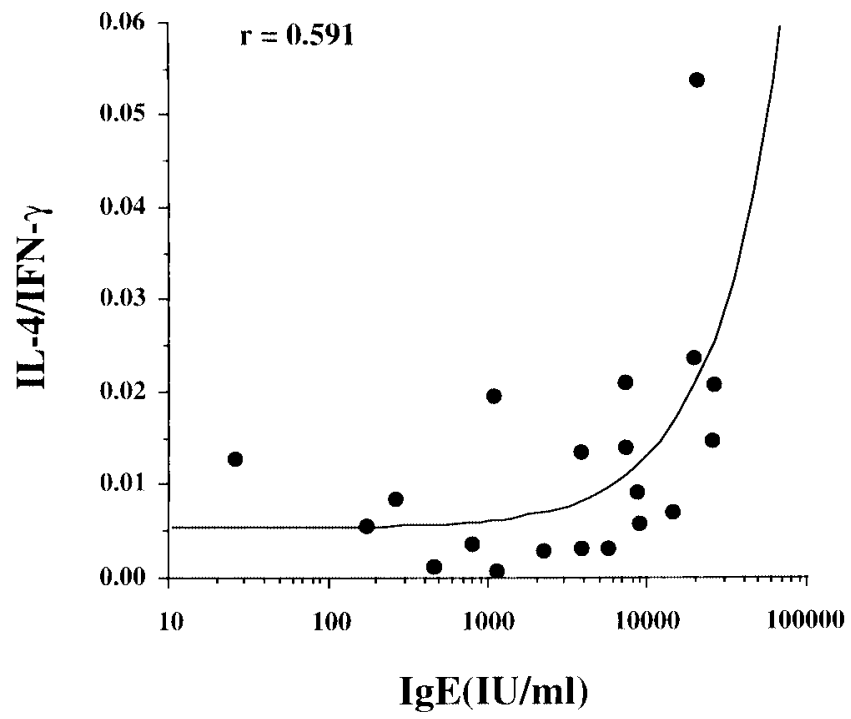

Fig. 4 Correlation of serum IgE with the ratio of IL-4/IFN- $\gamma$ produced by Con-A-stimulated peripheral blood mononuclear cells. The serum IgE level was measured by means of ELISA, as was the synthesis of IL- 4 or IFN- $\gamma$ by Con-A-stimulated peripheral blood mononuclear. The ratio of IL-4/IFN $\gamma$ is plotted against the serum IgE level.
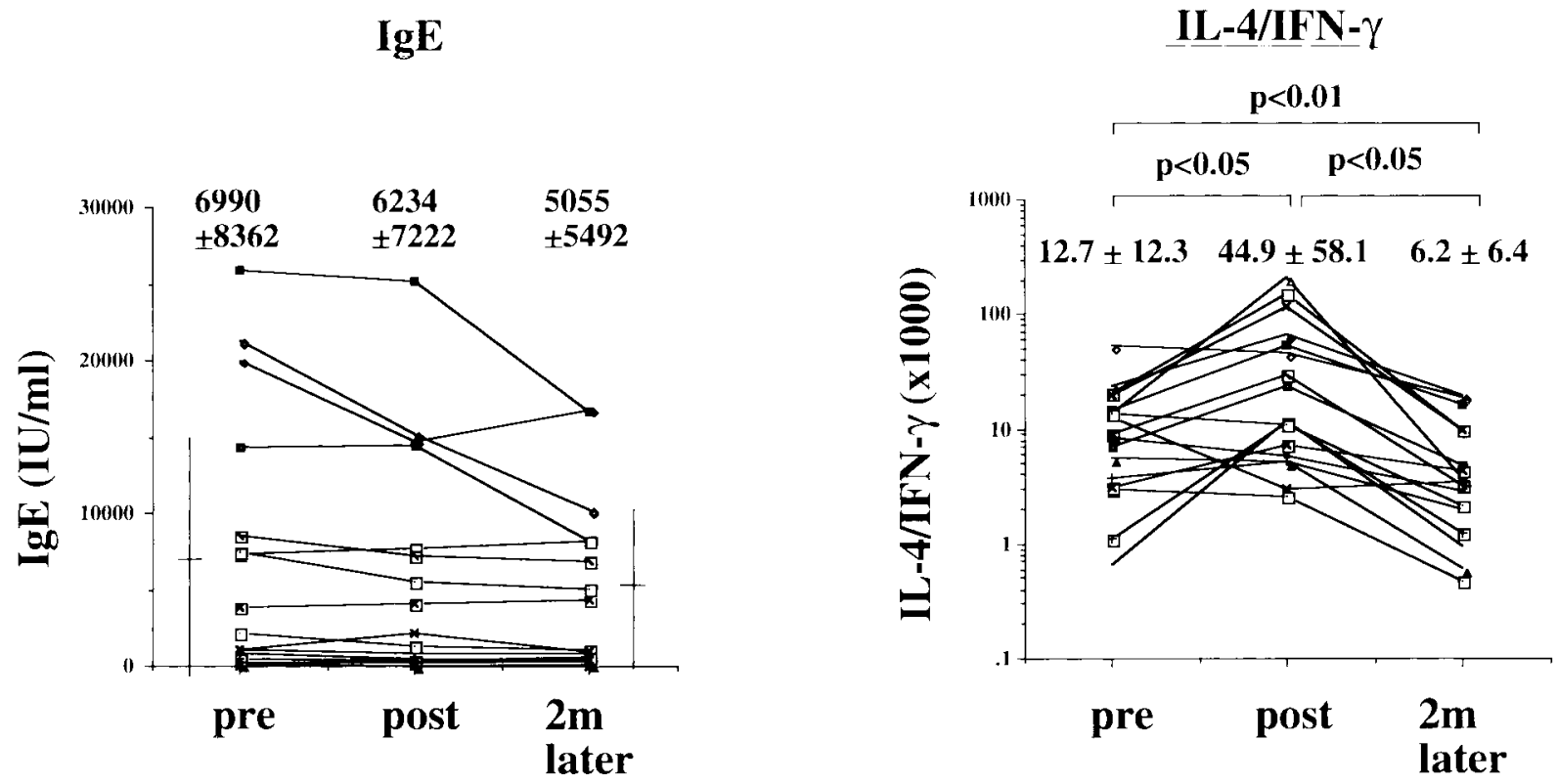

Fig. 5 Changes in serum IgE level and the ratio of IL-4/IFN- $\gamma$ synthesis before, just after and 2 months after cessation of the treatment. Serum IgE level and IL-4/IFN- $\gamma$ synthesis by peripheral blood mononuclear cells were measured by means of ELISA in 17 patients. Two months after cessation of the treatment, both levels had significantly decreased.

contributes to skin inflammation, IgE synthesis and preferential Th2 differentiation (Grewe et al., 1982; Hanifin et al., 1995). Fig. 7 shows that this synthesis was significantly suppressed during hospitalization. The ratio of PGE2/monocytes also decreased. 


\section{NK activity}

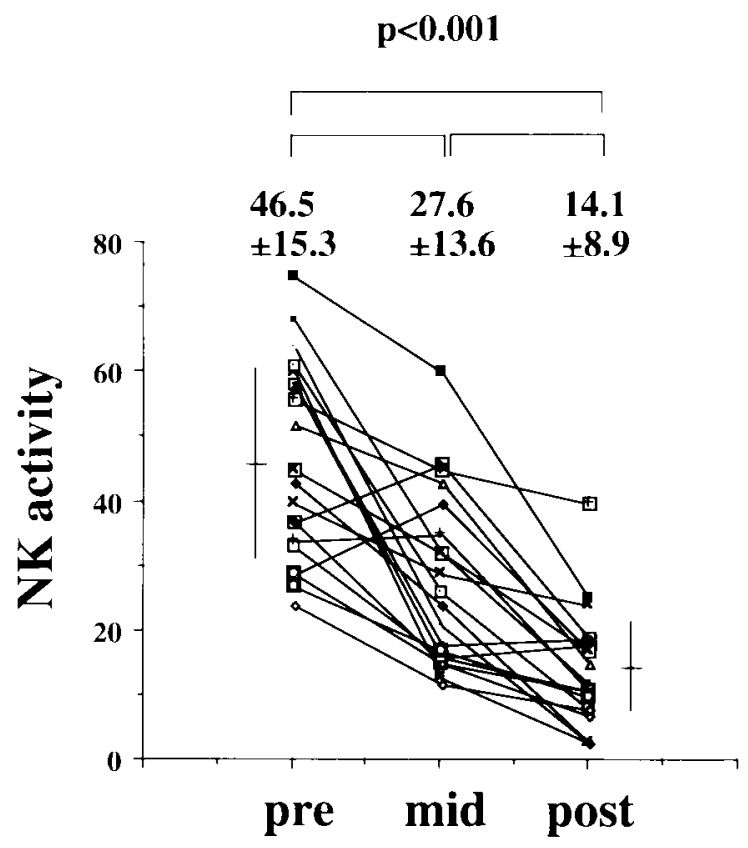

Number of neutrophils

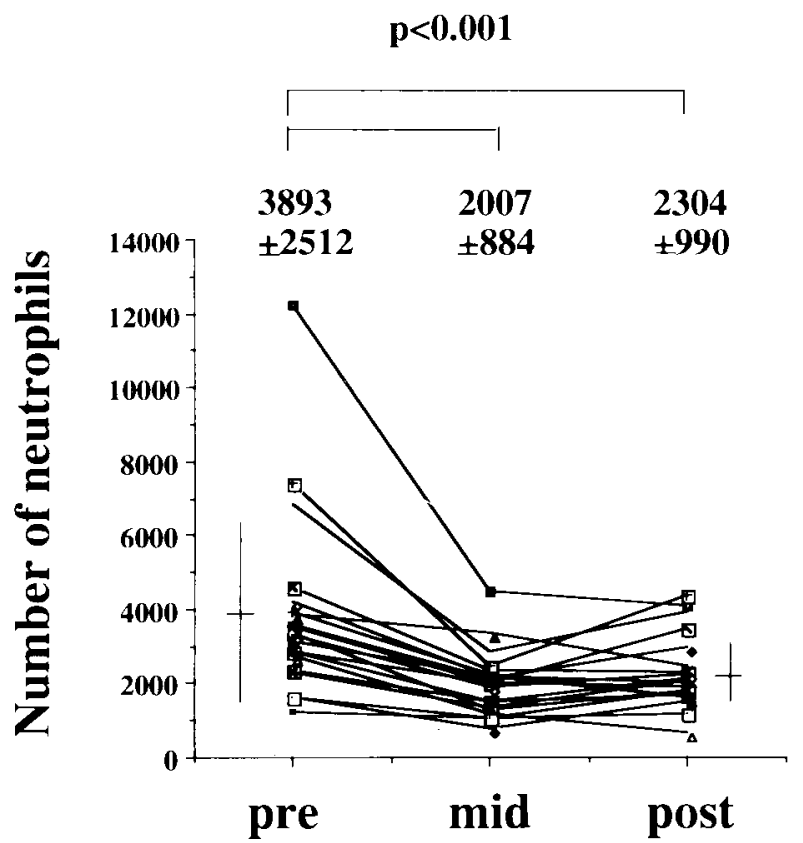

Fig. 6 NK activity and the number of peripheral neutrophils decreased. NK activity was assayed in terms of the activity of killing radiolabeled K562 cells. The treatment induced a gradual reduction in NK activity and a sharp drop in the number of neutrophils (cells/ $\mu \mathrm{l})$.
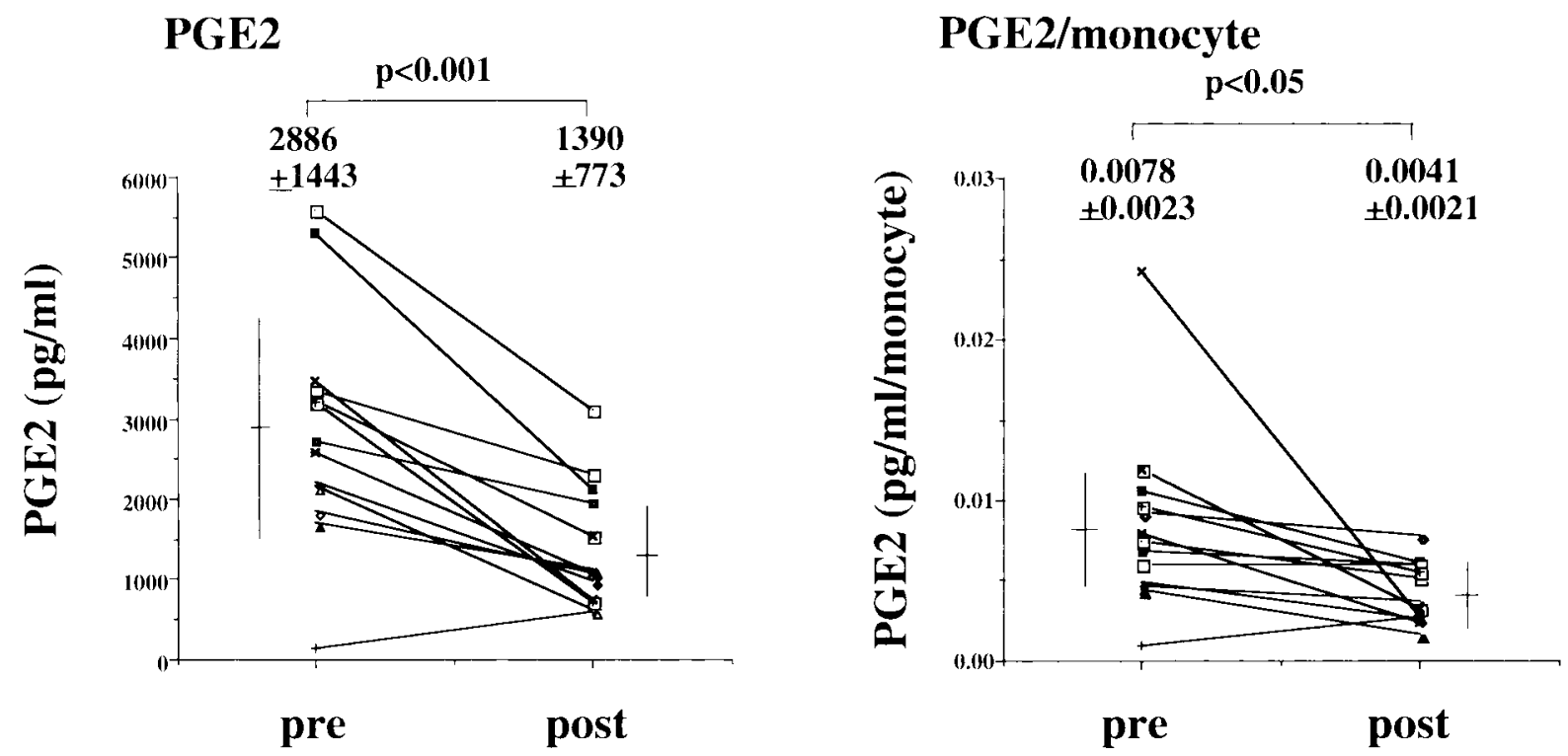

Fig. 7 Spontaneous synthesis of PGE2 was inhibited. PGE2 synthesis by unstimulated peripheral mononuclear cells was measured by means of ELISA. The panel on the left shows the change in PGE2 synthesis by whole mononuclear cells and the one on the right shows the change in PGE2 synthesis divided by the number of peripheral monocytes. Both levels decreased significantly. 
Changes in SCORAD or other markers after cessation of the therapy

Skin symptoms were examined 2 months after discharge. The SCORAD index had increased by $27 \%$ to 30.8 two months after discharge (Fig. 3). This increase was accompanied by an increase in LDH activity and in eosinophils. Total IgE, which had not changed during hospitalization, declined during the follow-up phase. In addition, the number of peripheral blood neutrophils returned to normal and the ratio of IL-4/IFN- $\gamma$ synthesis by Con-A-stimulated $\mathrm{T}$ cells was below the initial level (Fig. 5).

\section{Discussion}

Although substantial clinical progress has been made in the treatment of $\mathrm{AD}$, most patients with severe $\mathrm{AD}$ are still not satisfied with conventional treatment, which consists of topical or systemic steroids, anti-histamines, anti-allergic drugs and intensive skin care (Cooper, 1994; Leung et al., 1997; Graham-Brown, 1997; Rudikoff, 1998). Recently it has been verified that immunosuppressive drugs such as cyclosporin-A or azathiopurin are effective for this disease (Swoden et al., 1991; Tan, 1997). In addition, tacrolimus (FK-506) ointment is now used (Rutzicka et al., 1997). Evening primrose oil (linoleic acid and $\gamma$-linolenic acid), n-3 fatty acid supplement or Chinese herbal tea were found to have a substantial effect on AD (Wright and Bruton, 1982; Bjorneboe et al., 1989; Sheehan et al., 1992). In spite of these drugs and supplements, which can be expected to control atopic dermatitis, it is a fact that many patients prefer alternative treatments in the belief that they have fewer side effects. However, most of these alternative regimens have not been evaluated.

This study was carried out to evaluate the effectiveness of one regimen, which is basically made up of a lowenergy and vegetarian diet. The therapy suppressed skin inflammation to a significant degree. For instance, this treatment showed effectiveness for atopic dermatitis, equivalent to the clinical effect of cyclosporin-A (Sowden et al., 1991), although it took 2 months in hospital to achieve $50 \%$ reduction of skin symptoms. However, which component (low energy or its quality) is responsible for which effect remains to be determined. As for the effectiveness of the diet for $\mathrm{AD}$, it is accepted that allergen-eliminating diets are useful for children with AD who are sensitive to food allergens (Sampson, 1992). However, few reports deal with vegetarian diets as therapy for AD. Mabin et al demonstrated that the nutritional content of a few foods diet, supplemented with a casein hydrolysate formula or a whey hydrolysate formula, showed a greater than $20 \%$ improvement in the skin severity score of children with AD (Mabin et al., 1995). Thus it is possible that the vegetarian diet is in part responsible for the improvement seen in this study.

Previously we reported that this therapy caused a reduction in oxidative DNA damage measured by urinary secretion of 8-OHdG (Kouda et al., 2000). In this study to assess the mechanisms in more detail through which this therapy affected $\mathrm{AD}$, several immunological markers were examined. The number of eosinophils and neutrophils decreased prior to amelioration of dermatitis. Since eosinophils are inflammatory cells, which in part form dermatitis (Liferman et al., 1985; Kapp, 1993; Liferman, 1994), it is conceivable that the decrease in their number is one of the reasons for the ameliorative effect. Previous studies reported that a low calorie diet or fasting causes a reduction in the number of neutrophils in the peripheral blood (Powanda, 1977), so that, a low calorie diet may also be related to a reduction in the number of eosinophils, although it has not been demonstrated previously. In addition, the production of IL-5 by Con-A-stimulated peripheral blood mononuclear cells was also inhibited. LDH5, the number of peripheral eosinophils and the serum level of IgE have been proven to be activity markers for the severity of AD. Indeed, as shown in Fig. 1, there was a good positive correlation between the SCORAD index and these parameters. With the improvement in clinical symptoms, LDH5 decreased proportionally, although the serum IgE level did not change. In addition, the capacity of peripheral blood $\mathrm{T}$ cells to synthesize IL-4/IFN- $\gamma$ somewhat increased while NK activity decreased. Thus, from the viewpoint of Th1/ Th2 theory (Cooper, 1994; Grewe et al., 1998), preferential development of Th2 cells at least in the peripheral blood has not been inhibited by the therapy and thus may not offer an explanation for the improvement. Recently, it has been shown that fasting inhibits the synthesis of Leptin and that this molecule shows an activity of differentiation of naive $\mathrm{T}$ cells into Th1 cells (Lord et al., 1998). The reduction in the synthesis of IFN- $\gamma$ and peripheral NK activity observed during the hospitalization of our study subjects may be due to this mechanism.

Hanifin et al previously showed that the activity of phosphodiesterase was excessive in the monocytes from patients with atopic dermatitis (Grewe et al., 1982; Hanifin et al., 1995), resulting in the excess secretion of PGE2. Since PGE2, by acting on B cells, can induce IgE synthesis and enhance the preferential induction of Th2 cells from naive $\mathrm{T}$ cells, it was suggested that this molecule might be a key to the immunological abnormality in AD. The therapy used in our study suppressed the synthesis of PGE2 by peripheral monocytes, and two months after cessation of this therapy, the IgE level and Th1/Th2 balance had improved. Whether inhibition of PGE2 synthesis can lead to this immunological improvement or what causes inhibition of PGE2 synthesis remains unknown at the 
present time.

In summary, the therapy of a special vegetarian diet used in this study appears to be a useful alternative therapy for AD. Its effectiveness is possibly the result of inhibition of eosinophil differentiation and of PGE2 secretion by monocytes.

\section{References}

Bjorneboe A, Soyland E, Bjorneboe GE, Rajka G, Drevon CA (1989) Effects of n-3 fatty acid supplement to patients with atopic dermatitis. J Intern Med 225 (suppl 1): 233-236

Bos JD, Kapsenberg ML, Smitt JH (1994) Pathogenesis of atopic eczema. Lancet 343: 1338-1341

Cooper KD (1994) Atopic dermatitis: recent trends in pathogenesis and therapy. J Invest Dermatol 102: 128137

Endou K (1996) Folk remedies: present status and problems. Therapy for atopic dermatitis. SentanIgakusya, Tokyo, 178-188 (in Japanese)

Eskinazi D, Hoffman FA (1998) Progress in complementary and alternative medicine: contribution of the National Institutes of Health and the Food and Drug Administration. J Altern Complement Med 4: 459467

European Task Force on Atopic Dermatitis (1993) Severity scoring of atopic dermatitis: The SCORAD index-consensus report of the European task force on atopic dermatitis. Dermatol 186: 23-31

Graham-Brown RA (1997) Therapeutics in atopic dermatitis. Adv Dermatol 13: 3-31

Grewe M, Bruijnzeel-Koomen CA, Schopf E, Thepen T, Langeveld-Wildschut AG, Ruzicka T, Krutmann J (1998) A role for Th1 and Th2 cells in immunopathogenesis of atopic dermatitis. Immunol Today 19: 359-361

Grewe SR, Chan SC, Hanifin JM (1982) Elevated leukocyte cyclic AMP-phosphodiesterase in atopic disease: a possible mechanism for cyclic AMP-agonist hyporesponsiveness. J Allergy Clin Immunol 70: 452457

Hamid Q, Boguniewicz M, Leung DY (1994) Differential in situ cytokine gene expression in acute versus chronic atopic dermatitis. J Clin Invest 94: 870-876

Hanifin JM, Rajka G (1980) Diagnostic features of atopic dermatitis. Acta Dermatovener 92 (suppl): 44-47

Hanifin JM, Chan SC (1995) Monocyte phosphodiesterase abnormalities and dysregulation of lymphocyte function in atopic dermatitis. J Invest Dermatol 105 (1 suppl): $84 \mathrm{~S}-88 \mathrm{~S}$

Imokawa G, Abe A, Jin K, Higaki Y, Kawashima M, Hidano A (1991) Decreased level of ceramides in stratum corneum of atopic dermatitis: an etiologic factor in atopic dry skin? J Invest Dermatol 96: 523-526
Kapp A (1993) The role of eosinophils in the pathogenesis of atopic dermatitis-eosinophil granule proteins as markers of disease activity. Allergy 48: 1-5

Katada Y, Tanaka T, Ochi H, Aitani M, Yokota A, Kikutani H, Suemura M, Kishimoto T (1996) B cell-B cell interaction through intercellular adhesion molecule-1 and lymphocyte functional antigen-1 regulates immunoglobulin E synthesis by B cells stimulated with interleukin-4 and anti-CD40 antibody. Eur J Immunol 26: $192-200$

Kay J, Gawkrodger DJ, Mortimer MH, Jaron AG (1994) The prevalence of childhood atopic eczema in a general population. J Am Acad Dermatol 30: 35-39

Kouda K, Tanaka T, Kouda M, Takeuchi H, Takeuchi A, Nakamura H, Takigawa M (2000) Low-energy diet in atopic dermatitis patients: clinical findings and DNA damage. J Physiol Anthropol 19: 225-228

Kouda M (1995) Real health starts with wasting light: love and beneolence toward all forms of life gives you energy. Communica Inc. Tokyo

Leiferman KM, Ackerman SJ, Sampson HA, Haugen HS, Venencie PY, Gleich GJ (1985) Dermal deposition of eosinophil-granule major basic protein in atopic dermatitis; Comparison with onchocerciasis. N Eng J Med 313: 282-285

Leiferman KM (1994) Eosinophils in atopic dermatitis. J Allergy Clin Immunol 94 (6 Pt 2): 1310-1317

Leung DY (1993) Role of IgE in atopic dermatitis. Curr Opin Immunol 5: 956-962

Leung DY, Hanifin JM, Charlesworth EN, Li JT, Bernstein IL, Berger WE, Blessing-Moore J, Fineman S, Lee FE, Nicklas RA, Spector SL (1997) Disease management of atopic dermatitis: a practice parameter. Joint task force on practice parameters, representing the American Academy of Allergy, Asthma and Immunology, the American College of Allergy, Asthma, and Immunology, and the Joint Council of Allergy, Asthma and Immunology. Work Group on Atopic Dermatitis. Ann Allergy Asthma Immunol 79: 197-211

Leung DYM (1997) Atopic dermatitis: immunobiology and treatment with immune modulators. Clin Exp Immunol 107: 25-30

Lord GM, Matarese G, Howard JK, Baker RJ, Bloom SR, Lechler RI (1998) Leptin modulates the T-cell immune response and reverses starvation-induced immunosuppression. Nature 394: 897-901

Mabin DC, Sykes AE, David TJ (1995) Controlled trial of a new food diet in severe atopic dermatitis. Arch Dis Child 73: 202-207

McHenry PM, Williams HC, Bingham EA (1995) Management of atopic eczema: workshop of the British Association of Dermatologists and the research unit of the Royal College of Physicians of London. BMJ 314: 843-847

Nishi K (1977) Live longer the Nishi health system way- 
prevent sickness, maintain health and treat ailments. Hawaii Nishi Kai Inc.

Powanda MC (1977) Changes in body balances of nitrogen and other key nutrients: description and underlying mechanisms. Am J Clin Nutr 30: 1254-1268

Przybilla B, Eberlein-Konig B, Rueff F (1994) Practical management of atopic eczema. Lancet 343: 1342-1346

Rudikoff D(1998) Atopic dermatitis. Lancet 351: 17151721

Ruzicka T, Bieber T, Schopf E, Rubins A, Dobozy A, Bos JD, Jablonska S, Ahmed I, Thestrup-Pedersen K, Daniel F, Finzi A, Reitamo S (1997) A short-term trial of tacrolimus ointment for atopic dermatitis: European Tacrolimus Multicenter Atopic Dermatitis Study Group. N Eng J Med 337: 816-821

Sampson HA (1992) Food hypersensitivity and dietary management in atopic dermatitis. Pediatr Dermatol 9: 376-379

Sheehan MP, Rustin MHA, Atherton DJ, Buckley C, Harris DW, Brostoff J, Ostlere L, Dawson A (1992) Efficacy of traditional Chinese herbal therapy in adult atopic dermatitis. Lancet 340: 13-17

Sowden JM, Berth-Jones J., Ross JS, Motley RJ, Marks R, Finlay AY, Salek MS, Graham-Brown RA, Allen BR, Camp RD (1991) Double-blind, controlled, crossover study of cyclosporin in adults with severe refractory atopic dermatitis. Lancet 338: 137-140

Tan BB (1997) Azathioprine in dermatology: a survey of current practice in the UK. Br J Dermatol 136: 351-355

Williams HC (1995) On the definition and epidemiology of atopic dermatitis. Dermatol Clin 13: 649-657

Wright S, Burton JL (1982) Oral evening-primose-seed oil improves atopic eczema. Lancet 2: 1120-1122

Yamamoto S (1999) Therapeutic guidelines for atopic dermatitis. Allergy-ka 8: 491-496 (in Japanese)

Received: June 18, 2001

Accepted: September 6, 2001

Correspondence to: Toshio Tanaka, Department III of Internal Medicine, Osaka University Medical School, 2-2 Yamada-oka Suita City, Osaka 565-0871, Japan

e-mail: ttanak@imed3.med.osaka-u.ac.jp 